\title{
Design of a Small Fisheries Research Vessel with Low Level of Underwater-Radiated Noise
}

\author{
Yasuo YOSHIMURA (Graduate School of Fisheries Sciences, Hokkaido University), \\ Yasunari KOYANAGI (Division of Fisheries Consultant, Kyokuyo Co., Ltd.) \\ y-yoshi@ fish.hokudai.ac.jp \\ (Received at Jan. 13, 2004)
}

Abstract:

It is important for a fisheries research vessel to reduce the underwater-radiated noise. In 1995, the International Council for the Exploration of the Sea (ICES) firstly recommended the maximum noise level for research vessels to ensure the acoustic research works and to prevent the fish reaction against the noise ${ }^{1)}$. Since then, it has been the world standard for the design of fisheries research vessels. For a small size vessel, however, it is very difficult to achieve the recommendations because of not enough space or capacity to make sound insulations. Moreover, the Froude number $(F n)$ of such small vessels tends to be higher than that of the larger vessels. Since the higher Froude number of the operating condition causes the large wave-making resistance, both propeller thrust and occurrence of cavitation increase, which tends to result in the higher level of underwater-radiated noise. Meanwhile, the fisheries research-cost can be reduced by using a small vessel, because not only the construction and operation cost, but also maintenance cost become lower than those of a large vessel. It would be desirable and efficient if a small vessel could satisfy the ICES's recommendation in place of a large research vessel.

In this paper, the authors propose a design method for a small research vessel to reduce the underwater-radiated noise level. Utilizing this method, a small fisheries research vessel whose capacity is $290 \mathrm{GT}$ and length is $33.5 \mathrm{~m}$ has been designed. From the sea trials after the construction, it has been proved successfully that the underwaterradiated noise level is the world lowest class at 10 knots $(F n=0.28)$ of researching speed and still satisfies the ICES's recommendation even in 11.6 knots $(F n=0.33)$ of the high-speed region.

Classification: Fishery and Bioacoustics, Ship acoustics

Keyword: Underwater-radiated noise, fisheries research ship, propeller cavitation, ICES standard

\section{Introduction}

For a small research vessel, the hull resistance coefficient becomes higher than that of a large vessel even in the same ship speed, because the Froude number of the small vessel becomes high. Since the Froude number of the operating condition becomes higher, wave- making resistance increase, which often causes the propeller cavitation and the high level of underwater-radiated noise. Moreover, for the small research vessels, there is a little space to counter measure the machinery noises of engines and other machine plants. Therefore, it is generally disadvantageous for the small research 
vessels to reduce the underwater-radiated noise.

As for the underwater radiated-noise of fisheries research vessels, the level is requested to be as lower as possible to keep the performance of acoustic surveying instruments such as an integrated fish finder. Moreover, many fishes are so sensitive to the noise in the low frequency region that the noise level must be limited to prevent the fish avoidance against the noise. For this purpose, ICES recommended the maximum level of the underwater-radiated noise for a fisheries research vessel as shown in Fig. $1^{1}$. The recommendation consists of two parts as described bellow.

$$
\begin{aligned}
& N L(\mathrm{~dB} \text { re. } 1 \mu \mathrm{Pa} \text { at } 1 \mathrm{~m}) \\
& =\left\{\begin{array}{l}
135-1.66 \log \left(f_{H Z}\right) \quad:\left(1 \leq f_{H Z} \leq 1000\right) \\
130-22 \log \left(f_{H Z} / 1000\right):\left(1,000 \leq f_{H Z} \leq 100,000\right)
\end{array}\right.
\end{aligned}
$$

The criterion in the low frequency region $\left(1<f_{H z}<\right.$ $1,000)$ comes from the request of prevention of the fish avoidance, and in the high frequency region $(1,000<$ $\left.f_{H z}<100,000\right)$ from the acoustic survey capability, respectively. The detail of these criteria is described in the reference [1]. As researchers usually desire the satisfaction of the ICES's recommendation, resent fisheries research vessels have almost began to reflect this recommendation in their construction specifications.

In this paper, the authors discuss the noise sources and propose a design method to reduce the noise particularly for a small vessel, referring to the example of the small fisheries research vessel ${ }^{2)}$.

\section{Noise Sources and Design to Reduce Underwater Radiated Noise}

In order to design the vessel with low underwaterradiated noise, the noise sources and mechanisms are correctly grasped. For this purpose, the conceivable noise sources are summarized in Table 1 . These noise sources can be divided into two groups.

\subsection{Machinery Noise}

The first group is the machinery noise that comes from the vibration induced by the main engine, generator engine, gearbox and pumps installed in engine room. The frequency domain of this noise is generally less than $10 \mathrm{kHz}$. To reduce underwater-radiated noise from diesel engines, suitable rubber beds must be selected. As for the gearbox of main engine, it sometimes makes a significant noise peak around $1 \mathrm{kHz}$ as shown in the example in Fig. 2, and then the rubber beds must be also installed here. In this case, it is necessary to design the suitable mass-spring system to

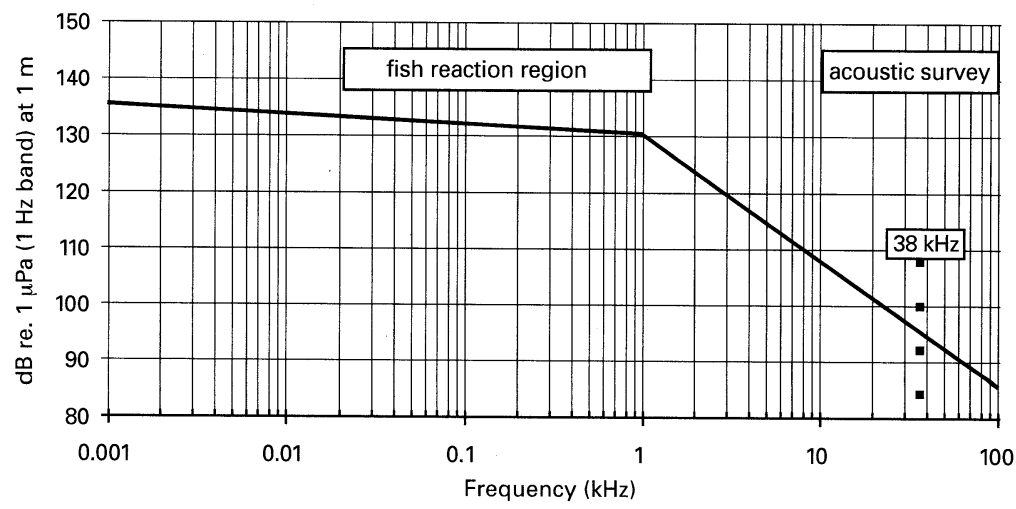

Fig. 1 Recommended maximum underwater-radiated noise level by ICES at 11 knots free-running for all vessels used in fisheries research ${ }^{1)}$. 
Table 1 Noise sources and design against the noise.

\begin{tabular}{|c|c|c|}
\hline Noise source & Frequency domain & Design against the noise \\
\hline $\begin{array}{l}\text { Propulsion Engine } \\
\text { Generator Engines } \\
\text { Gearbox, Pumps }\end{array}$ & $\sim 10 \mathrm{kHz}$ & $\begin{array}{l}\text { (1) Noise absorbing bed and suspension } \\
\text { (2) Low-noise type machine } \\
\text { (3) Hull damping material }\end{array}$ \\
\hline Propeller cavitation & $1 \mathrm{kHz} \sim 100 \mathrm{kHz}$ & $\begin{array}{l}\text { (4) Keep enough propeller tip clearance } \\
\text { (5) Reduction of propeller load } \\
\rightarrow \text { Reduction of hull resistance (EHP) } \\
\text { 1) Optimum ship hull dimensions } \\
\text { 2) Optimum Cp curve } \\
\text { 3) Bulbous bow } \\
\text { (6) Smoothing the wake pattern around the propeller } \\
\rightarrow \text { Adopt stern bulb \& fine frame line } \\
\text { (7) Highly skewed propeller } \\
\text { (8) Low rpm \& large diameter of propeller } \\
\text { (9) Deep propeller immersion }\end{array}$ \\
\hline
\end{tabular}

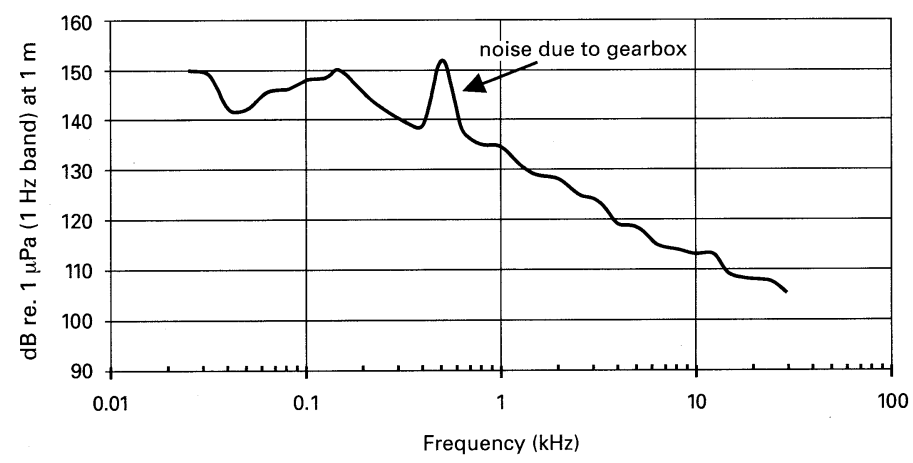

Fig. 2 An example of underwater-radiated noise spectrum by a gearbox ${ }^{1)}$.

avoid a torsional vibration, because the main engine and the gearbox are connected by an elastic coupling. As the machinery noises are mainly produced in engine room, it is useful to coat a damping paint inside of the ship hull of engine room. This kind of hull damping material is already in market and easy to be applied.

\subsection{Propeller Cavitation Noise}

The frequency domain of propeller cavitation noise is from $1 \mathrm{kHz}$ to $100 \mathrm{kHz}$ and significantly disturbs the acoustic instruments. In order to reduce the pro- peller cavitation noise, the following design procedures are required as described in Table 1.

As for the reduction of propeller load, it is necessary to reduce the hull resistance obviously. For this purpose, more precise design for the propulsive performance is required taking the acoustic characteristic of the ship into the consideration in principal design stage. The following processes are required.

- Optimisation of ship hull parameters to determine ship dimensions such as $L / B, B / d, C b, C p$ 
- Optimisation of $C p$ curve of ship (longitudinal volume profile of ship)

- Utilization of the appendages to reduce the ship resistance such as bulbous bow

Although $L / B, B / d, C b, C p$ are important parameters to determine the hull form and the stability of ship, it is necessary to chose the values as to be minimum in hull resistance. Particularly for the small fisheries research vessel where the Froude number becomes higher, these parameters must be selected in order to minimize the wave-making resistance. For the optimisation of $C p$ curve and the appendages to reduce the ship resistance, experimental tank tests, potential theories or recent computational fluid dynamics (CFD) techniques are used.

\section{(1) Estimation of cavitation area}

To estimate propeller cavitation noise by Brown's method $^{3)}$, it is necessary to find out cavitation area on the propeller blades. Although the precise characteristic of propeller cavitation is not easy to be predicted using the cavitation tunnel test, the cavitation area can be roughly estimated by the following empirical method. Fig. 3 shows the relations among the thrust load coefficient $\tau$, cavitation number $\sigma$ and back cavitation area ratio that is defined by the total area of cavitation on the backside (ship side) blade against the propeller disk area. The definitions of the vertical axis $\tau$ and the horizontal axis $\sigma$ are as follows:

$$
\begin{aligned}
& \tau=T /(\rho / 2) A_{p}\left\{V_{a}^{2}+\left(0.7 \pi n D_{p}\right)^{2}\right\} \\
& \sigma_{0.7 \mathrm{R}}=(p-e) /(\rho / 2)\left\{V_{a}^{2}+\left(0.7 \pi n D_{p}\right)^{2}\right\}
\end{aligned}
$$

$$
\begin{aligned}
& \text { where } T \text { : propeller thrust } \\
& \rho \text { : density of water } \\
& A_{p}: \text { propeller disk area } \\
& V_{a} \text { : inflow velocity to propeller } \\
& n \text { : propeller revolution per sec. }
\end{aligned}
$$

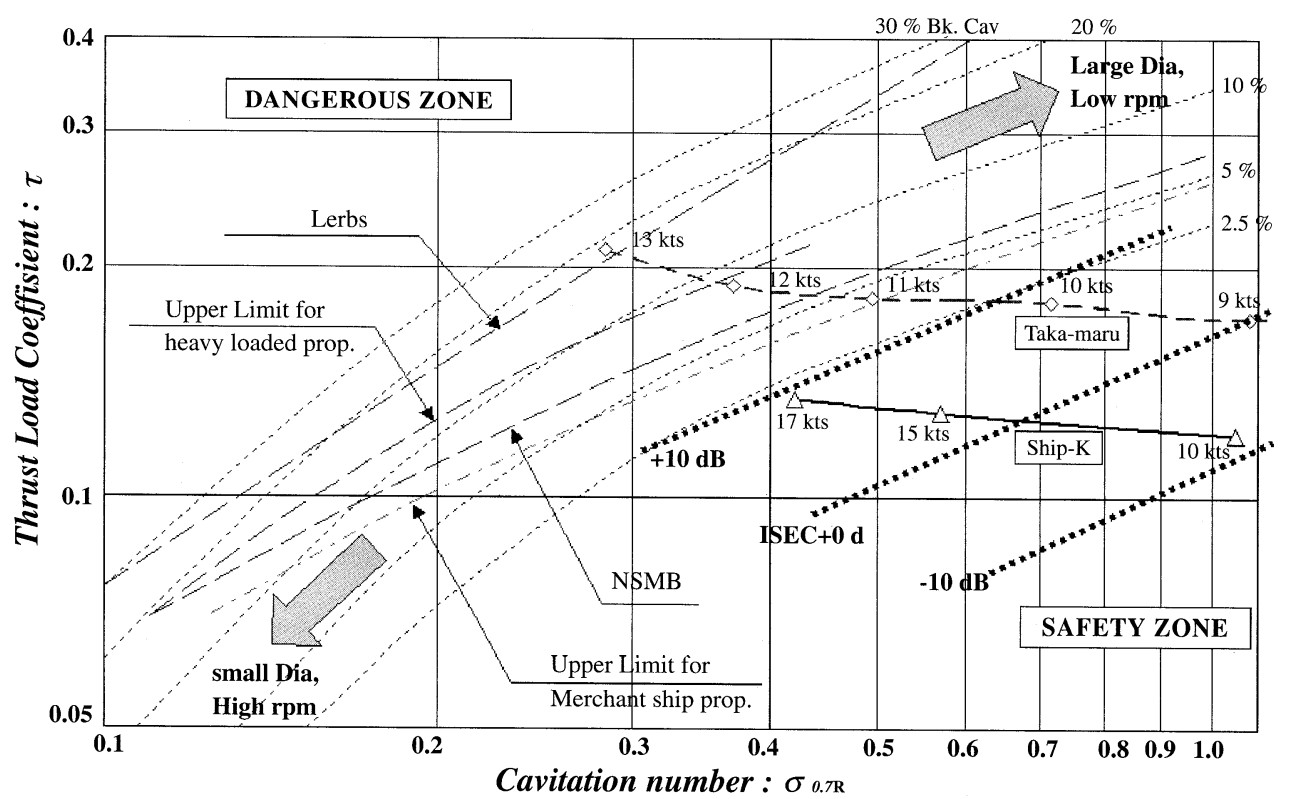

Fig. 3 Empirical relations among thrust load coefficient, cavitation number and back cavitation area with dotted bold lines for the under-water radiated noise level at acoustic survey. 


$$
\begin{array}{ll}
D_{P}: \text { propeller diameter } \\
p \quad: \text { static pressure at propeller center line } \\
e \quad: \text { vapor pressure of water }
\end{array}
$$

When $\tau$ becomes high and $\sigma_{0.7 \mathrm{R}}$ low, the propeller back cavitation tends to occur strongly in the upper left side in this figure. This chart is well known as Burrill's chart ${ }^{4)}$, but will be used for the empirical estimation of cavitation area. In this figure, the estimated $\tau$ and $\sigma_{0.7 \mathrm{R}}$ of recent fisheries research vessels ${ }^{5-7)}$ are plotted with ship's speed as parameters. For Ship-K, that is the large fisheries research vessel, $\tau$ and $\sigma_{0.7 \mathrm{R}}$ at 10 knots of free-running $(F n=0.18)$ locates in the lower right side of this figure, where the ship resistance and thrust load coefficient are very small. For 'Taka-maru' that is a small fisheries research, the result at 8 knots of free running $(F n=0.26)$ also shows the similar characteristics. The measured underwater-radiated noise levels of the above-mentioned two vessels are approximately $-10 \mathrm{~dB}$ from the maximum level by ICES in high frequency region. It can be seen that the $\tau-\sigma_{0.7 \mathrm{R}}$ characteristics of these successfully designed ships locate at less than $1 \%$ of back cavitation area on the Burrill's chart. Although the relations between $\tau$ $\sigma_{0.7 \mathrm{R}}$ characteristics and underwater-radiated noise levels are few, it can be pointed out that the $\tau-\sigma_{0.7 \mathrm{R}}$ characteristic also corresponds to the underwater-radiated noise level empirically as described by the following formula.

$$
\tau=\left\{\begin{array}{l}
0.110 \sigma_{0.7 R}^{(2 / 3)}(\text { for the max imumlevel by ICES }-10 \mathrm{~dB}) \\
0.165 \sigma_{07 R}^{(2 / 3)}(\text { for the max imumlevel by ICES }+0 \mathrm{~dB}) \\
0.215 \sigma_{0.7 R}^{(2 / 3)}(\text { for the } \max \text { imumlevel by ICES }+10 \mathrm{~dB})
\end{array}\right.
$$

These characteristics are plotted by the bold dotted lines in Fig. 3. Using this figure, the suitable $\tau-\sigma_{0.7 \mathrm{R}}$ relation for the required level of the underwater-radiated noise can be roughly grasped. The relation between back cavitation area and the corresponding noise level can be also estimated.

The second important point to minimize the propeller cavitation is the smoothing of the wake pattern at the propeller disk. For this purpose, keeping enough clearance of propeller tip and hull, adoption of stern bulb and fine stern frame are necessary. For a small fisheries research vessel, however, the aft frame lines tend to expand because of the demand from the enough space in engine room and aft deck, which makes the wake pattern worse. In such cases, a high skew propeller can help to reduce the propeller cavitation.

\section{(2) Prediction of under-water radiated noise level}

The spectrum of underwater-radiated noise induced by the propeller cavitation can be predicted by Brown's method. The noise level: $N L(\mathrm{~dB}$ re. $1 \mu \mathrm{Pa}$ at $1 \mathrm{~m})$ is simply calculated as the following formula ${ }^{3)}$.

$$
\begin{aligned}
& N L(\mathrm{~dB} \text { re. } 1 \mu \mathrm{Pa} \text { at } 1 \mathrm{~m}) \\
& =163+10 \log _{10}\left(z D_{p}^{4} n^{3} / f_{H z}^{2}\right)+10 \log _{10}(A c / A d)
\end{aligned}
$$

where, $A c / A d$ : propeller back cavitation area ratio against the propeller disk area

$z$ : number of propeller blades

$f_{\mathrm{Hz}}$ : frequency in $\mathrm{Hz}$

In Fig. 4, the example of calculated noise levels are plotted with Ship-A that is the small fisheries research vessel mentioned later, assuming several back cavitation area ratios. In this figure, ICES's minimum recommendation line and the measured underwater-radiated noise spectra of the large fisheries research vessels "Dr. F. Nansen", "Corystes" and "Ship-K" are also plotted. From these comparisons, it is found that less than $10 \%$ of back cavitation area ratio is required to satisfy ICES's recommendation, and less than $1 \%$ of back cavitation area is required to achieve the world lowest level with the underwater-radiated noise. 


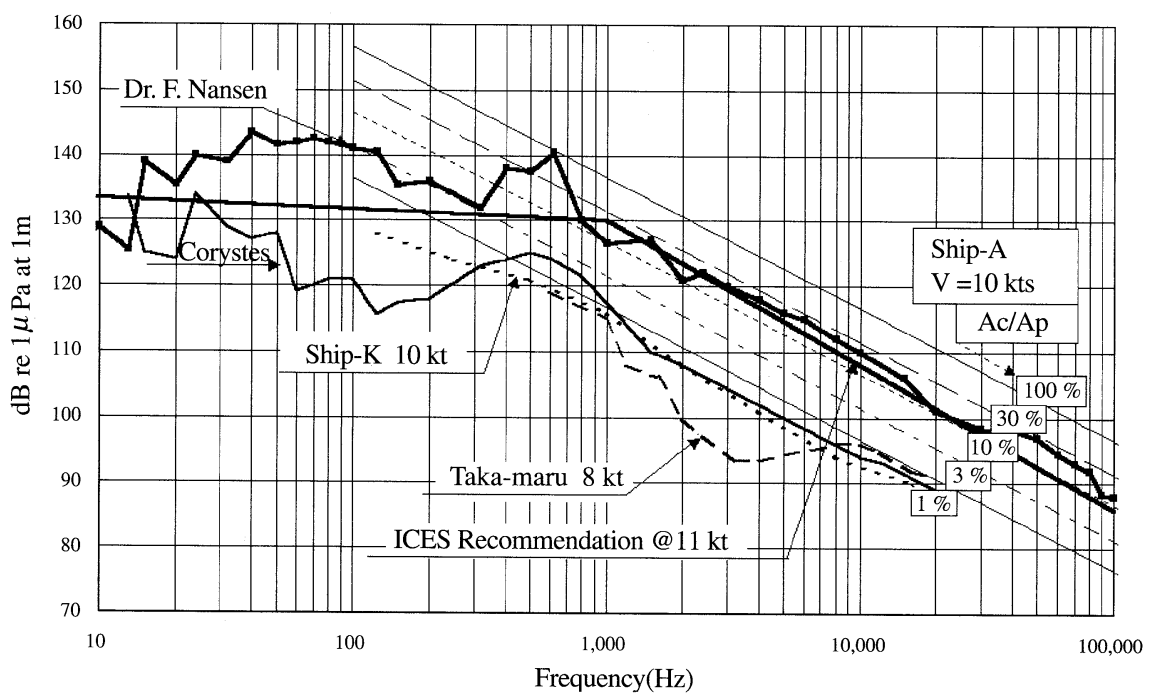

Fig. 4 Estimated underwater-radiated noise level of Ship-A by Brown's method.

\section{Example of Design and Construction of the Small Fisheries Ship}

The Ship- $\mathrm{A}^{2)}$, designed here, is a small fisheries research vessel with stern trawler. In designing this vessel, the reduction of underwater-radiated noise is aimed in order to prevent any trouble for the newest acoustic research equipments. For this purpose, the vessel's hull form under the water is sharply slimed and the hull damping material is applied for the reduction of machinery noise. In addition, the hull structure is designed so that the center of gravity becomes lower to secure the safety and stability. The principal particulars and the general arrangement are shown in Table 2 and Fig. 5 respectively.

Table 2 Principal particulars of Ship-A.

Length between p.p:

$$
\begin{array}{r}
33.50 \mathrm{~m} \\
7.80 \mathrm{~m} \\
3.50 \mathrm{~m} \\
3.00 \mathrm{~m} \\
293 \mathrm{t} \\
736 \mathrm{~kW} \\
13.18 \mathrm{knots} \\
12.2 \text { knots } \\
21 \text { persons }
\end{array}
$$$$
\text { Breadth (moulded): }
$$$$
\text { Depth (moulded): }
$$

Designed draft (moulded):

Main engine output:

13.18 knots

Maximum trial speed:

Complement

(Crew:14 persons, Scientists:7 persons)
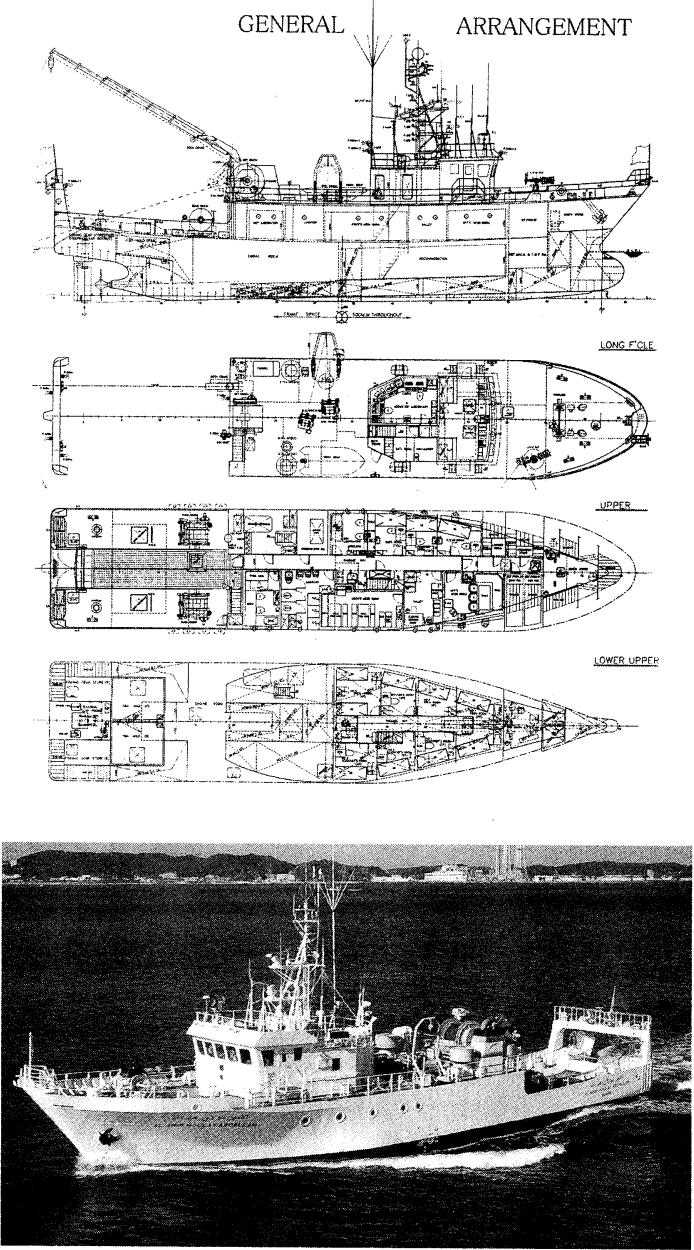

Fig. 5 Photograph and General arrangement of 'Ship-A'. ${ }^{2)}$ 


\subsection{Arrangements for the Reduction of Underwater-Radiated Noise Level}

In order to minimize the underwater-radiated noise level, almost all design procedures in Table 1 have applied.

For the reduction of machinery noise,

(1) Elastic rubber beds for main engine, generator engines and marine gearbox

(2) Installation of low noise type machine

(3) Application of damping paint to the inside shell of engine room

For reduction of the propeller cavitation noise,

(4) Optimum hull dimensions were selected and hull form including bulbous bow and fine sonar dome has been designed by utilizing the computer simulations and model tests in towing tank. The estimated $\tau-\sigma_{0.7 \mathrm{R}}$ characteristic for several ship speed are plotted in Fig. 6. One at 10 knots of free-running $(F n=0.28)$ locates in the lower right side of Burrill's chart, where the thrust load coefficient are small.
(5) Slimed stern frame and hanging rudder without shoe piece, for the purpose of the smoothing of the wake pattern around the propeller position

(6) More than $25 \%$ propeller diameter of the propeller tip clearance is kept.

(7) Optimum dimensions including high skew are selected for low rotation with large diameter propeller.

\subsection{Result of the Measurement of Under- water-Radiated Noise}

The measured spectra of underwater-radiated noise at 10 and 11.6 knots free-running speed of Ship-A are shown in Fig. 7, where the measured spectra of the fisheries research vessel "Corystes", "Dr. F. Nansen" are shown for comparison. These vessels are the typical fisheries research vessels whose underwater-radiated noise level are lowest class in the world, and contributed to the establishment of ICES's recommendation. Besides, the propulsion system of "Corystes" is electric motor driven and called the ship with the world lowest noise level. These vessels are listed in Table 3.

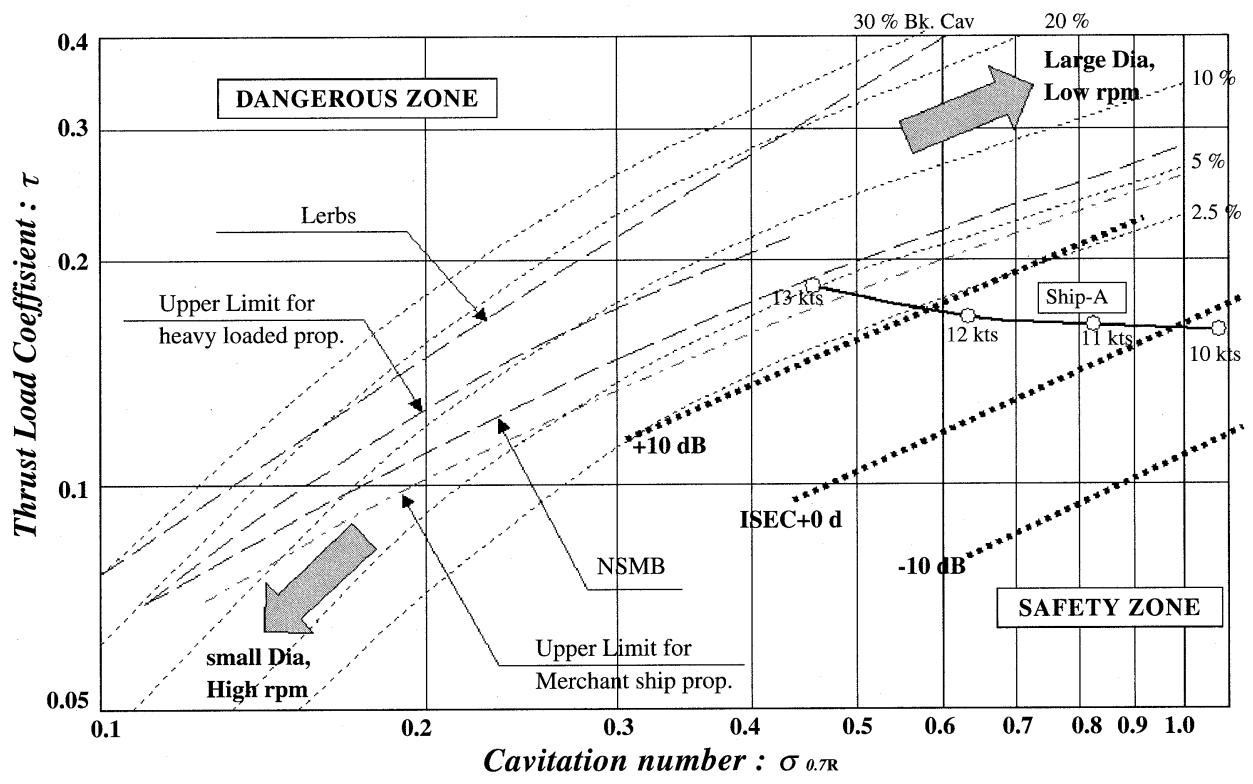

Fig. 6 Estimated $\tau-\sigma_{0.7 \mathrm{R}}$ characteristic of Ship-A. 


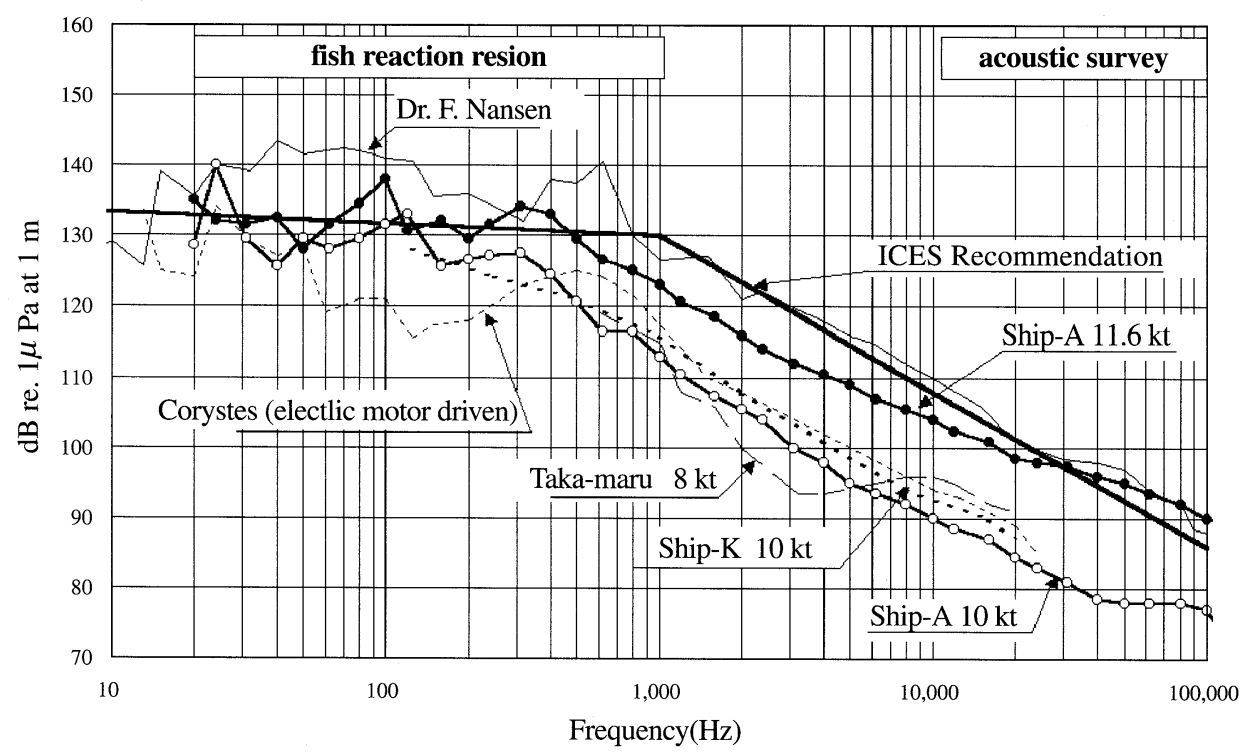

Fig. 7 Measured underwater-radiated noise spectrum of Ship-A.

Table 3 Comparison of researching speed and ship size that satisfy the ICES's recommendation.

\begin{tabular}{l|l|r|r|l}
\hline & \multicolumn{1}{|c|}{ Ship Size } & Speed (kts) & $F n$ & \multicolumn{1}{|c}{ Propulsion Unit } \\
\hline \multirow{2}{*}{$\begin{array}{l}\text { Ship-A } \\
\text { (designed Ship) }\end{array}$} & $L p p=33.5 \mathrm{~m}$ & 10 & 0.28 & \multirow{2}{*}{ Diesel with CPP } \\
\hline Taka-maru & $L p p=25.0 \mathrm{~m}$ & 11.6 & 0.33 & \\
\hline Corystes & $L p p=48.992 \mathrm{~m}$ & 8 & 0.26 & Diesel with CPP \\
\hline Dr. F. Nansen & $L o a=56.75 \mathrm{~m}$ & 11 & 0.26 & Electric Motor, FPP \\
\hline Ship-K & $L p p=83.0 \mathrm{~m}$ & 11 & 0.26 & Diesel with FPP \\
\hline
\end{tabular}

From this figure, it is pointed out that the level of measured noise spectrum of Ship-A at 10 knots $(F n=0.28)$ is lower than that of "Corystes" in the wide frequency range of over $500 \mathrm{~Hz}$. Even in 11.6 knots ( $F n=0.33$ ) of high-speed free running, the measured noise level is still lower than that of "Dr. F. Nansen".

\section{Conclusion}

In the design of the fisheries research vessel, it is important to reduce the underwater-radiated noise in order to ensure the acoustic research works and prevent the fish avoidance against the noise. The authors summarize the essence of the design techniques to reduce the underwater-radiated noise level based on the measured full-scale noise data and empirical formulas. The concluding remarks are the followings.

1) For the reduction of machinery noise, it is useful to adopt elastic rubber beds and hull damping material.

2) The optimum hull dimensions and hull form are necessary to minimize the resistance of ship. The reduction of the propeller thrust loading, adoption of the slimed fine stern frame and the selection of optimum propeller dimensions including high skew are effective to reduce the occurrence of propeller cavitation.

3) Although the accurate prediction is difficult, 
Brown's formulas with the extended Burrill's chart (Fig. 3) are very useful for the prediction of the cavitation noise level.

4) Utilising these methods, the small fisheries research vessel that satisfies the ICES's recommendation was designed successfully.

\section{Acknowledgement}

The authors would like to express great gratitude to Dr. Takao Sasajima who was the chairman of The Marine Acoustics Society of Japan. They obtained many technical assist and instruction from him for this paper. Unfortunately, he passed away in the sudden subway accident in 2003 . Here, they sincerely pray for the bliss of the dead.

\section{References}

1) R. B. Miston, "Underwater noise of research vessels review and recommendations", ICES Cooperative Research Report., 209, (1995).
2) Y. Koyanagi, "Design and construction of the fisheries research vessel [AL AMIR MOULAY ABDALLAH]", Journal of Fishing Boat and System Engineering Association of Japan, 1(2), 2738 (2002).

3) N. A. Brown, "Cavitation noise problems and solutions", International Symposium on Shipboard Acoustics, (1976).

4) W. P. A. Van Lammeren, "Propulsion and Steering of Ships", 186, (1948).

5) H. P. Knudsen, E. Ona, I. Svellingen, "Hydro acoustic performance of new fisheries research vessels", Symposium on Fisheries and Plankton Acoustics, (1995).

6) Y. Hatayama, "Fisheries research vessel of national research institute of fisheries engineering Taka-maru, Journal of Fishing Boat Association of Japan, 318, 74-94 (1995).

7) Fishery Agency of Japan, "Fisheries research vessel Wakatka-maru", Journal of Fishing Boat Association of Japan, 319, 1-43 (1995). 